\title{
Imbalances in the Capital of Credit Institutions as a Source of Instability in the Economy and in the Market of Loans Issued to Subjects of the Real Sector of the Economy
}

\author{
M.S. Maramygin ${ }^{1}, E . V$. Strelnikov $^{1}$, and $S . Y$. Arzumanyan $^{2}$ \\ ${ }^{1}$ Ural State University of Economics, 620144 Ekaterinburg, Russia \\ ${ }^{2}$ Financial State Tashkent Institution, Tashkent, Uzbekistan
}

\begin{abstract}
In the present paper, the study of imbalances in the capital structure of some Russian banks is carried out. The very imbalances in the structure of commercial banks have a significant impact on the dynamics of the entire banking and loan market in the country. And in particular, the dynamics of the development of the agricultural sector. The study of the uneven structure of the balance sheets of commercial banks allowed us to draw conclusions. First, the uneven balance of the bank can be expressed both in a positive and negative plane, depending on the size of the capital imbalance, it can be concluded that the size of the imbalance is naturally dependent and the effect of influence on the dynamics of the formation of reserves for the loan portfolio. Second, analysis of various operations of commercial banks, in particular the analysis of banking operations, transactions of a credit institution and other transactions allows us to divide the services of the Bank for various type of clients from significant to insignificant to have an impact on possible alleged imbalance in the Bank, which can affect the imbalance in the lending industry for the real sector of the economy, particularly the imbalances in lending to agribusiness. The cumulative growth of these imbalances in several banks can lead to an unstable situation in the loan market. The fight against possible imbalances in the capital of banks can lead to an increase in the stability of the loan market and the stability of the entire economic system as a whole. This will stabilize the market of loans to the real sector of the economy and the market of loans issued within the framework of the agro-industrial complex.
\end{abstract}

\section{Introduction}

Risks of stability of the banking system as the main factor of stability of the loan and financial market are the most important and significant problematic moments in the development of the modern financial market. stability and instability in the financial market as a whole and in the loan market as a segment of the financial market depends on the level and degree of risk of financial stability of the market mechanism. in turn, the increase in the risk of financial stability can be associated with several factors. in modern economics, the most frequently considered factors are, first, the factors associated with the emergence of problems in the main participants of the loan market, for example, the problems associated 
with the emergence and development of holes in the capital of commercial banks; secondly, it is the possible development of a new equilibrium state in the loan market, which can form slightly different risks in the financial and loan market. moreover, in the process of developing any of these trends in the construction of loan and financial market risks, the role and place of the bank's problems in generating such risks is not entirely clear. The problem of identifying and ranking banks according to the level of development of the "hole" of discrepancy between active and passive operations of the bank should be defined more precisely in the banking system and in the market as a whole. The most important problem in terms of the possible emergence of new risks in the loan market may be the emergence and development of new capital mismatches of credit institutions.

An imbalance in the balance sheets of several credit institutions can have a significant impact on the development of imbalances in the loan market as a whole, which can be regarded by the market, i.e. its participants, as a signal for a possible future shock in the market. In Addition, such a process may increase. The strengthening or weakening of its role may be associated with the development of cyclical processes in the market. The cyclical nature of the market can multiply, depending on the size of these imbalances in the structure of the balance sheets of commercial banks. Imbalances as a source of instability of the entire financial market are still presented as Terra incognita in the study of risk theory. Despite the fact that the cause of the economic crisis of 2008-2009 was precisely the presence of imbalances among certain participants in the financial market, the opinion about their impact on the stability of the entire market remains relatively approximate and requires further research. at the same time, in the financial market, it is possible to observe a quite logical situation when different participants in the loan market react differently to the situation of significant imbalances in the capital structure of some banks, for example, there is an imbalance in the market associated with the redistribution of cash flows that generate profit of credit institutions. The process of profit redistribution can be one of the catalysts and reasons for the redistribution of risks in the banking system, which inevitably affects not only the risk profile of the relevant credit institution, but also affects the instability and instability of the entire loan market. In the modern economy, a number of authors consider the combination of internal and external shocks in the market as one of the main systemic financial risks in the economy of the Russian Federation [1]. Some authors come to the conclusion about the relationship between internal and external shocks in these periods of market development. But, unfortunately, a small number of authors consider the financial market as an integral system, which can plunge into a state of instability and chaos due to relatively small problems in the balance sheet of an individual financial institution.

\section{Materials and Methods}

In order to assess the level and degree of influence of imbalances, we applied the best practices and methods presented by $\mathrm{m}$. Mamov in a series of articles devoted to the study of holes in the capital of banks in the context of their activities for 5-10 years, during the period of active revocation of licenses of credit institutions, which presumably ended in 2019. The main methodology is the method used by M. Mamonov - this is the Hecnman's model, which was introduced in 1979 [5]. Such models may differ from standard comparison models in that they can adjust the initial coefficients for both active operations and for the main operations that make up the bank's liability balance sheet. In our case, in parallel with this model, a stability coefficient is introduced, which implies an assessment of the level of change in the ratio of toxic and non-toxic assets on the market. in addition to the introduced stability coefficient, the models proposed by heckman were used in this paper, as previously noted. 
In this paper, we used data obtained using the Heckman model, using the selection equation and the exchange equation. In turn, the selection equation allows us to identify the possibility of future mismatch of active and passive operations in the bank in some dynamics, which leads to an increase in the imbalance in the bank's capital structure.

This model allows you to divide different participants according to the degree of their relationship to the bank, i.e. it can be legal entities and individuals, for example, as $\mathrm{M}$. Mamonov notes, households and enterprises. It is most preferable in this perspective to divide clients in relation to the bank into financial and non-financial agents [8].

This study considers the stabilization coefficient in the projection of the bank's activity and the stability of the financial market as a whole.

However, before using all these methods of regulating the financial market, i.e. directly applying the paradigm of market stabilization, it is necessary to conduct preliminary testing of the financial market. The proposed stabilization coefficient is quite suitable for this purpose:

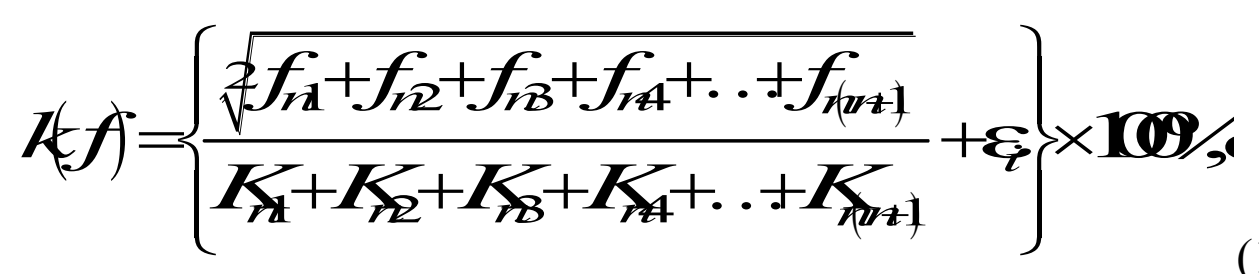

where $\mathrm{k}(\mathrm{f})$ is the coefficient of stabilization of financial assets;

$f_{n 1}$

- volume of "toxic" assets in the capital market;

fin

- volume of "toxic" assets in the loan market;

F

- volume of "toxic" assets in the stock market;

Fit

- volume of "toxic" assets in the foreign exchange market;

F(mal)

- volume of "toxic" assets in a certain segment of the financial market;

Fr

- volume of "uninfected" assets in the capital market;

Kre

- volume of" uninfected " assets in the loan market;

Trs

TA

- volume of " uninfected " assets in the stock market;

- volume of" uninfected " assets in the foreign exchange market;

Fint

- the volume of" uninfected " assets in a certain segment of the financial market;

$\xi$

- the average square deviation of the assets of the financial markets used.

In this case, the detoxification coefficient is a kind of indicator that can be used to determine how much the financial market or a certain segment of it is affected by instability and the appearance of default components. The coefficient shows the ratio of the volume of "toxic" assets in the financial market (financial markets) to the aggregate of "non-toxic", not subject to "contamination" of financial assets. The volume of assets for each market should be applied in comparable units of measurement-US dollars (million, billion US dollars). In order for the value of the proposed index to correspond to the true state of affairs in the financial market, the value of the mean square deviation was included in the formula. 
The detoxification rate varies from 0 to $100 \%$. In crisis situations, with an abundance of defaults, an increase in the detoxification rate of up to $150 \%$ can be observed. This raises a fair question: what assets can be classified as "toxic"? In our opinion, "toxic" assets may include assets for which the obligation has not been fulfilled at least once. For example, in the case of the loan market, the category of "toxic" assets can include a loan for which at least once during the term of the obligation a late payment was made; in relation to the stock market, a "toxic" asset can be, for example, a bond for which the issuer has not fulfilled its obligations at least once, or for which there is a real possibility that the issuer will not fulfill its obligations to creditors (this, in particular, may be indicated by a downgrade of the security's rating by one point).

The level of possible market imbalance and its dependence on the toxicity of the asset used in the loan market should be directly related.

The study was based on data from the website of the Bank of Russia on 300 banking institutions for the period from 01.01.2018 to 01.01.2019.

\section{Results and Discussions}

According to the results of the study, it can be said that the most important components of the system under consideration are the dynamics of active and passive operations of banks.

Table 1. Imbalances in the capital of banks in the Russian loan market, by the stabilization coefficient*

\begin{tabular}{|c|c|c|}
\hline № & Name & Value, \% \\
\hline 1 & Credit and deposit operations of the bank(financial agents) & $-8,4--10,6$ \\
\hline 2 & Stabilization ratio & $56,6-61,2$ \\
\hline 3 & Credit and deposit operations of the bank(not financial agents) & $-14,3--17,8$ \\
\hline 4 & Stabilization ratio & $76,3-87,5$ \\
\hline
\end{tabular}

* Table 1 presents data on imbalances in the balance sheet structure of credit institutions and the ratio with the possible value of the stabilization coefficient in the market.

Based on the results of the analysis of Table 1, some conclusions can be drawn. in particular, attention is drawn to the presence of a fairly significant imbalance between the operations of financial and non-financial agents in the context of the ratio of active/passive operations and the resulting stability index. It can be noted that the ratio of loans to deposits from financial agents generates a significantly lower risk of destabilization than that of nonfinancial organizations.

This situation is most likely due to the fact that, in the aggregate, the volume of transactions with non-financial organizations in the balance sheet of the banks considered is much larger. The table also does not show the dynamics of these operations by the urgency of the corresponding operations. For example, according to $\mathrm{M}$. The volume of imbalances in the bank's capital will decrease slightly as the urgency of the bank's operations increases, for example, for credit operations for a period of up to 1 year, the standard imbalance will be $11.9 \%$, for the same operations, but with an urgency of more than 3 years, the imbalance for existing banks will correspond to $10.6 \%$. But at the same time, the minimum values of imbalances can be $70-90 \%$, which actually correlates in some way with the presented data [6]. within the framework of this study, it can also be noted that the probability t projection of imbalances in the bank's capital can significantly affect the market as a whole and attract the emergence of a situation of instability in the loan market as a whole [2]. 
In addition, according to the presented data, it is possible to draw an ambiguous conclusion that in many credit institutions you can find cases of conscious or unconscious concealment of the fact of the possible occurrence of a potential hole in the capital. This may be one of the possible justifications for such an increase in the stability index.

In addition, although this was not presented in this study, both external and internal shocks in the market have a rather negative impact on the process of creating imbalances in banks. At the same time, in aggregate, a large share of market imbalances can have a significant negative impact on the structural features of both the loan market and the financial market as a whole.

The level and degree of imbalance in the capital of banks directly depends on the level of risk of assets with which the bank conducts both active and passive operations.

As previously noted, the data on various urgent operations of banks in the context of possible generation of crisis phenomena in the economy are quite interesting. Crisis phenomena in the economy can have a direct impact both on the formation of holes in the capital of banks, and on the possible redistribution of priorities of banks in the use of these resources in their operations. However, the proposed research can make a guess on the possible use of the stabilization factor, which can, with some degree of success to be applied in assessing the level or degree of possibility of a situation of instability in the financial market

Based on the results of the calculations of the stabilization coefficient (CS) for all groups of indicators for assessing the stability of the market, the level of their deviation from the established standard values is determined for each of the indicators. Further, by the expert method, the values, depending on the degree of their deviation from the standard value in accordance with the 100-point scale of the author's methodology (Table 2), are assigned points taking into account the weight of each indicator. the maximum number of points is the best score, and the minimum number is the worst score.

Table 2 . Scale of assessment of the stabilization coefficient depending on the level of the bank's capital problems

\begin{tabular}{|l|c|}
\hline \multicolumn{1}{|c|}{ CS } & Evaluation criteria, \% of banks in the entire market structure \\
\hline from 0 to 20 & $\begin{array}{c}\text { Assigned in case of possible instability in the market associated with an imbalance in the } \\
\text { bank's capital structure, 1-20\% of banks }\end{array}$ \\
\hline from 21 to50 & $\begin{array}{c}\text { Assigned in case of possible instability in the market associated with an imbalance in the } \\
\text { bank's capital structure, } 20 \text { to } 49 \%\end{array}$ \\
\hline from51 to 70 & $\begin{array}{c}\text { Assigned in case of possible market instability associated with an imbalance in the bank's } \\
\text { capital structure, 50-59\% }\end{array}$ \\
\hline from 71 to 99 & $\begin{array}{c}\text { Assigned in case of possible market instability associated with an imbalance in the bank's } \\
\text { capital structure, } 60-99 \%\end{array}$ \\
\hline 100 & $\begin{array}{c}\text { Assigned in case of possible market instability associated with an imbalance in the bank's } \\
\text { capital structure, } 100 \%\end{array}$ \\
\hline
\end{tabular}

According to Table 2, the following conclusions can be drawn. The stabilization coefficient and its value are important for evaluation, if the stabilization coefficient is in relatively acceptable indicators, i.e. within $20 \%$, then the structure of the loan market will contain up to $20 \%$ of banks with possible capital holes, which may subsequently have a negative impact on the stability of the loan market as a whole.

The source of the unstable state of the market may be related to some factors, for example,

- if banks attract sufficiently significant deposits from non-financial agents, and these resources occupy a significant share in the resource base of banks, sometimes, but not always, such credit institutions find other sources of resources, but the imbalance in the bank's capital cannot be immediately eliminated, so this can have a significant impact on the structure of not only the bank's capital, but also the loan market as a whole, and it also has a significant impact on the stability of the financial market; 
- in the case of even a small composition of such operations, for example, even if the main imbalances in the capital structure of a single credit institution can be observed to have a significant impact on the stability and stability of the entire loan market, for example, even if $1 \%$ of commercial banks will have problems with capital, the stabilization coefficient can be assigned in the amount of $20 \%$, which will have a significant role in the stability of the loan market.

Stability at such a fairly low level of instability may seem implausible, but in this regard, we can refer to the experience of crisis situations in the economy in 2008-2009 and in 2014. So initially, the share of banks that had imbalances was no more than 5\%. But in the development of the situation, practice has shown that this share has grown significantly, i.e. even a small share of imbalances can lead to significant instability in the market as a whole.

\section{Conclusion}

Thus, the imbalance in the loan market may be related to the extent to which the bank's capital contains a mismatch of assets and liabilities of the balance sheet. Even with a low level of non-compliance, i.e. with a low degree of occurrence of holes in the capital of individual banks on the market, with a fairly high degree of probability can come instability, which will have a destabilizing impact on the economy in General and agriculture in particular. in addition, instability in the loan market can be measured relatively successfully using the stabilization coefficient, which is defined as the ratio of toxic and non-toxic assets.

\section{References}

1. M. Mamonov, Voprosy ekonomiki, 7, 42 (2017)

2. M. Mamonov, Money and Credit, 77(1), 51 (2018)

3. M. Mamonov, Voprosy ekonomiki, 5, 49 (2018)

4. M. Mamonov, Money and Credit, 79(2), 70 (2020)

5. M. Mamonov, J. of the New Economic Association, 1(37),112 (2018)

6. M. Mamonov, Economic Issues, 6, 30 (2019)

7. F. Kostrov, M. Mamonov, BOFIT Discussion Papers, 6 (2019)

8. P. Puhani, J. of Economic Surveys, 14(1), 53 (2000) 